\title{
Stature estimation of the Malaysian population based on sacrum CT scans
}

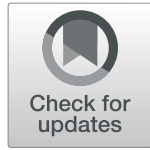

Lai Poh Soon', Mohamad Helmee Mohamad Noor ${ }^{1}$, Nurliza Abdullah ${ }^{3}$ and Helmi Hadi ${ }^{*}$ (D)

\begin{abstract}
Background: The evolution of virtual technology in estimating stature through multi-slice computed tomography scanning can be essential for mass disasters and forensic cases. Regression formulae were generated directly from other skeleton parts such as cranium, sternum, vertebrae, clavicle, scapula, sacrum, pelvis, hand and foot bones to estimate stature. Previous studies have shown that pelvic shape score is significantly associated and correlated with stature for both sexes. The sacrum as part of the pelvis is located between the two os coxae via a sacroiliac joint. As such, this study aims to correlate the morphological measurement of sacrum with stature based on sex and ancestry among the Malaysian population from a total of 373 sacral computed tomography (CT) images collected at the Kuala Lumpur Hospital. The three-dimensional sacrum bones were segmented from CT images using the Mimics Research 17.0 software. Inter-landmark distances were measured using Microsoft 3D Builder, and their respective indices were computed.

Results: The auricular lengths are the most comparatively useful stature estimator at $R>0.5$ among all the sacral morphometrics that were investigated on in this study. Results from this study should only be applied within the Malaysian population (Malay, Chinese and Indian).

Conclusion: The results could enhance the existing database of stature estimation, especially when dealing with skeletal material from Malaysia and when long bones are unavailable for the identification of incomplete unknown human remains.
\end{abstract}

Keywords: Forensic anthropology, Sacrum, Stature estimation, Malaysian population

\section{Background}

The evolution of virtual technology to the present day is signified by the multislice three-dimension (3D) rendered CT scanning that is readily available to most forensic anthropologists, especially those attached to forensic mortuaries. Biological profiling from the anthropological approach comprises of data such as sex (male and female), ancestry or geographical origin (Negroid, Caucasian and Mongoloid), skeletal age and stature estimations (Linda, 2006). Living stature is defined as the maximum height attained during one's lifetime (Megan and Ann, 2013,

\footnotetext{
* Correspondence: helmi_mhp@usm.my

${ }^{1}$ Department of Forensic Science, School of Health Science, Universiti Sains Malaysia, Kubang Kerian, Malaysia

Full list of author information is available at the end of the article
}

Wiley, 2016). Living stature may possibly be predictable only after sex, ancestry and age have been assessed due to the varying levels of growth, sexual dimorphism, skeletal degeneration and population variation (Megan and Ann, 2013, Wiley, 2016).

Stature estimation was first conducted during the middle of the eighteenth century by Jean-Joseph Sue. It was further developed by Carl Pearson (Megan and Ann, 2013). Estimating stature can be essential for individuation in mass disasters and forensic cases (Özaslan et al., 2003). Both whole-skeleton and whole-limb-bone methods are usually utilised for stature estimation (Wiley, 2016). Nonetheless, one problem with those methods is that the requisite complete bones may be absent. The solution to the problem is to estimate the length of the present fragmented 
parts such as the limb bone or vertebral column by applying a regression formula (Megan and Ann, 2013, Wiley, 2016).

Stature estimation is normally calculated using the length of long bones, especially the lower limbs (Wiley, 2016). Since the early 1980s, regression formulae have been calculated for estimating stature directly from other skeleton parts such as cranium, sternum, vertebrae, clavicle, scapula, sacrum, pelvis, hand and foot bones (Wiley, 2016). As a part of the human appendicular skeletal system, the pelvic girdle (hip girdle) consists of the paired hip or pelvic bones (os coxae) connected anteriorly at the pubic symphysis through the cartilaginous element (Standring, 2015). The pelvic girdle is connected posteriorly with the sacrum to form the pelvis.

Pelvic shape score is significantly associated and correlated with stature for both sexes according to the Hamann-Todd collection (Barbara and Philipp, 2015). This correlation is nonetheless better for males compared to females. This statement is also applicable to sacrum height (Torimitsu et al., 2015, Barbara and Philipp, 2015, Pelin et al., 2005). A few studies on sacrum height used magnetic resonance imaging (MRI) and multi-slice computed tomography (MSCT) images to estimate total body height (Hakki et al., 2011, Pelin et al., 2005, Torimitsu et al., 2014). Males' sacrum height (SH) was also found to be significantly higher than females' (Hakki et al., 2011, Torimitsu et al., 2014). The correlation between sacral height and stature is significant in males only with the regression equation [stature = $(0.306 \times \mathrm{SH})+137.9]$ (Hakki et al., 2011). Although Torimitsu et al. (2014) reported a positive correlation in both sexes, all mentioned studies demonstrated comparatively moderate regression coefficients ranging from 0.4 to 0.6 only.

Multiple regression equations can be formed from several parameters to improve the regression coefficient (Pelin et al., 2005). Despite the numerous stature equations that have been developed for populations around the world, these equations cannot be applied to the Malaysian population as regression formulae are generally population-specific. Hence, there is always the need for additional population-specific reference data using mathematical methods and regression theory. As such, this study aims to correlate the sacral morphometric with stature based on sex and ancestry for the Malaysian population.

\section{Materials and methods Materials}

This study is a retrospective cross-sectional study of the sacrum which had obtained ethical approval (reference number KKM.NIHSEC.P18-2350(7)) and registered under the National Medical Research Registry (NMRR-
18-3132-44576) of the Ministry of Health, Malaysia. A total number of 373 CT Scan Digital Imaging and Communication in Medicine (DICOM) folders stored in the Picture Archiving and Communication Systems (PACS) from year 2010 to 2018 were retrieved retrospectively from post-mortem subjects of the National Institute of Forensic Medicine (NIFM) in the Kuala Lumpur Hospital $(\mathrm{KLH})$ and from living patient subjects of the Radiology Department of KLH. Post-mortem subjects were scanned with 2-blocks CT for the whole body using a Toshiba Aquilion 64 Post-mortem MSCT scanner at $2.0 \mathrm{~mm}$ resolution, whilst living patient subjects were selected from diagnostic scans that included $\mathrm{CT}$ abdomen, $\mathrm{CT}$ pelvic and $\mathrm{CT}$ urography with an average resolution of $1.0 \mathrm{~mm}$. The difference in resolution should be acceptable as it fulfils the minimum measurement requirements.

\section{Sampling}

Subjects were selected based on sex subgroups (male and female) and ancestry subgroups (Malay, Chinese and Indian) for each decade subgroup from 10 to 79 years old as summarised in Table 1. The sub-adult and adult stature were investigated together in order to cater for the relationship between the wider range of stature and sacral morphometrics, although it may have individual variation in terms of growth rate and sexual dimorphism. The sample size was calculated

Table 1 Subject distribution across sex, age and ancestry subgroups

\begin{tabular}{|c|c|c|c|c|c|}
\hline \multirow[t]{2}{*}{ Age groups } & \multirow[t]{2}{*}{ Sex groups } & \multicolumn{3}{|c|}{ Ancestry subgroups } & \multirow[t]{2}{*}{ Total } \\
\hline & & Malay & Chinese & Indian & \\
\hline \multirow[t]{2}{*}{$10-19$} & Male & 9 & 9 & 9 & 27 \\
\hline & Female & 9 & 8 & 6 & 23 \\
\hline \multirow[t]{2}{*}{$20-19$} & Male & 9 & 9 & 9 & 27 \\
\hline & Female & 9 & 9 & 9 & 27 \\
\hline \multirow[t]{2}{*}{$30-39$} & Male & 9 & 9 & 9 & 27 \\
\hline & Female & 9 & 9 & 9 & 27 \\
\hline \multirow[t]{2}{*}{$40-49$} & Male & 9 & 9 & 9 & 27 \\
\hline & Female & 9 & 9 & 9 & 27 \\
\hline \multirow[t]{2}{*}{$50-59$} & Male & 9 & 9 & 9 & 27 \\
\hline & Female & 9 & 9 & 9 & 27 \\
\hline \multirow[t]{2}{*}{$60-69$} & Male & 9 & 9 & 9 & 27 \\
\hline & Female & 9 & 9 & 9 & 27 \\
\hline \multirow[t]{2}{*}{$70-79$} & Male & 9 & 9 & 8 & 26 \\
\hline & Female & 9 & 9 & 9 & 27 \\
\hline \multirow[t]{3}{*}{ Subtotal } & Male & 63 & 63 & 62 & 188 \\
\hline & Female & 63 & 62 & 60 & 185 \\
\hline & Total & 126 & 125 & 122 & 373 \\
\hline
\end{tabular}




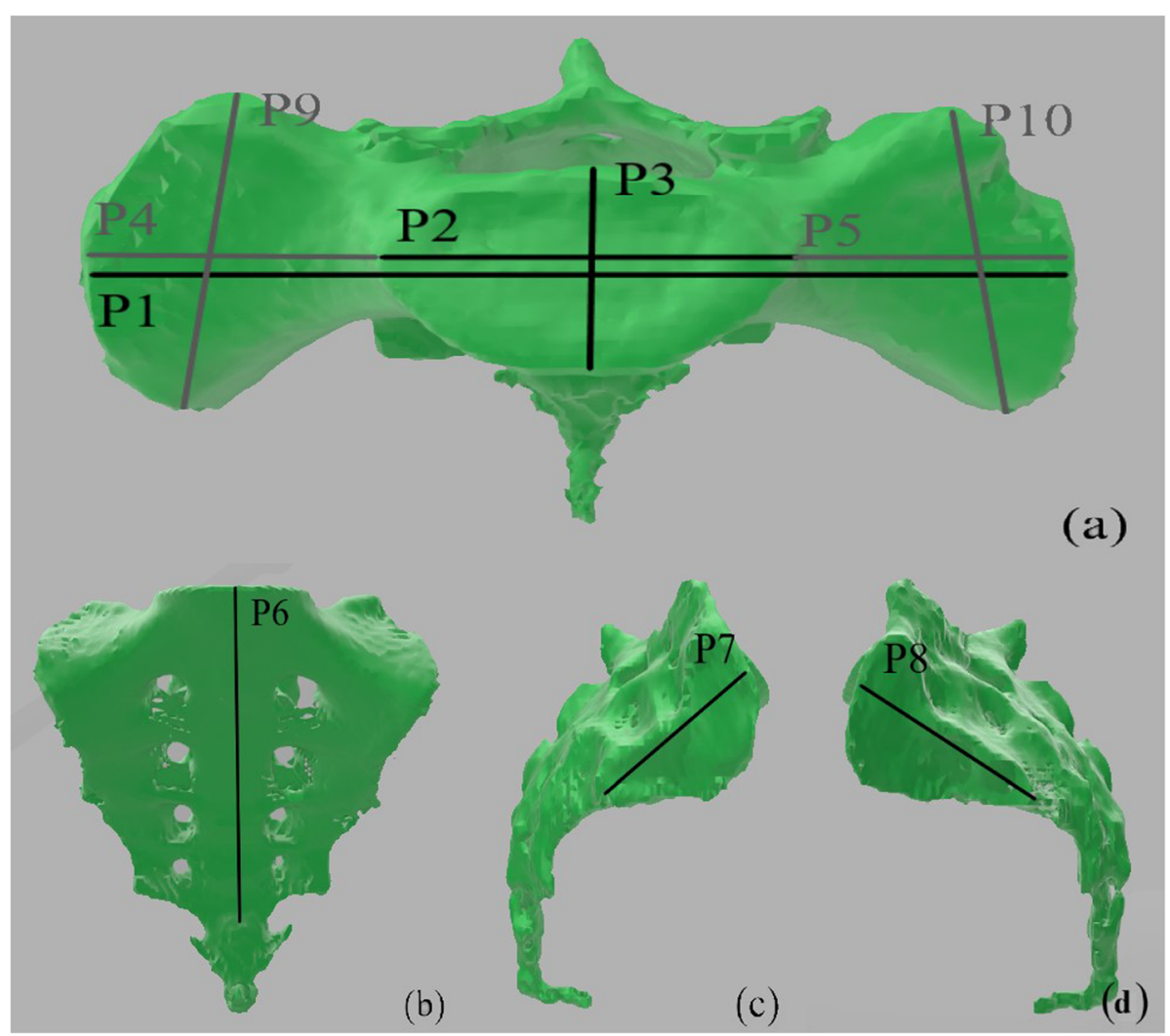

Fig. 1 Inter-landmark distances and parameters shown on the sacrum at superior view (a), anterior view (b), right lateral view (c) and left lateral view (d). Screenshots obtained from the Microsoft 3D Builder software (refer to Table 2 for the measurements of P1-P10)

using an online Raosoft ${ }^{\circ}$ sample size calculator (Raosoft, 2004) based on the parameter inputs including a margin of error at $5 \%$, confidence level at $95 \%$ and response distribution at $50 \%$ of the represented target population.
The DICOM files and the demographics of the samples were collected together with their respective known demographic data such as sex, age, ancestry and height. These demographic data were traced from the Forensic Medicine Information System (FMIS) or Patient

Table 2 Definition and description of sacrum parameters adopted from Kanika et al. (2011) and Shreekrishna et al. (2013) (refer to Fig. 1 for image description)

\begin{tabular}{|c|c|c|}
\hline No. & Parameter(s) & Description \\
\hline $\mathrm{P} 1$ & Sacral basal width & Maximum transverse midpoint distance of the superior surface of sacrum that comprising of the two alae \\
\hline P2 & Transverse diameter S1 body & Maximum transverse midpoint diameter of the articular surface of the body of first sacral vertebra (S1) \\
\hline P3 & $\begin{array}{l}\text { Anteroposterior (A-P) diameter } \\
\text { S1 body }\end{array}$ & $\begin{array}{l}\text { Antero-posterior distance from the midpoint of sacral promontory up to the midpoint on the posterior } \\
\text { border of S1 body }\end{array}$ \\
\hline P4 & Right ala width & Maximum straight distance of the right sacral ala from the right transverse diameter of the S1 body \\
\hline P5 & Left ala width & Maximum straight distance of the left sacral ala from the left transverse diameter of the S1 body \\
\hline P6 & Sacral height & The midpoint of the sacral promontory to the middle of antero-inferior border of the fifth sacral vertebra \\
\hline P7 & Right auricular surface length & Maximum distance of the superior-inferior inner border of auricular surface on right lateral aspect of sacrum \\
\hline P8 & Left auricular surface length & Maximum distance of the superior-inferior inner border of auricular surface on left lateral aspect of sacrum \\
\hline P9 & Right ala A-P length & $\begin{array}{l}\text { Antero-posterior distance from the lateral posterior most point up to lateral anterior most point on the } \\
\text { superior border of the right ala }\end{array}$ \\
\hline P10 & Left ala A-P length & $\begin{array}{l}\text { Antero-posterior distance from the lateral posterior most point up to lateral anterior most point on the } \\
\text { superior border of the left ala }\end{array}$ \\
\hline
\end{tabular}


Table 3 Definition and description of sacrum indices adopted from Kanika et al. (2011) and Shreekrishna et al. (2013)

\begin{tabular}{|c|c|c|c|}
\hline No. & Index(es) & Description & Formula \\
\hline 11 & Sacral index & Ratio of sacral basal width to sacral height (sacral mid-ventral straight length) (\%) & $P 1 \div P 6$ \\
\hline 12 & Corporobasal index & Ratio of transverse diameter of S1 body (corpus width) to sacral basal width of S1 (\%) & $P 2 \div P 1$ \\
\hline 13 & S1 body index & Ratio of anteroposterior (A-P) diameter to transverse diameter of S1 body (\%) & $P 3 \div P 2$ \\
\hline 14 & Alar base-wing index & Ratio of average bilateral ala width to transverse diameter of S1 body (\%) & $(P 4+P 5) \div 2 \div P 2$ \\
\hline 15 & Auricular index & Ratio of average bilateral auricular surface length to sacral basal width (\%) & $(P 7+P 8) \div 2 \div P 1$ \\
\hline 16 & Alar diagonal index & $\begin{array}{l}\text { Ratio of average bilateral ala width to average bilateral ala anteroposterior (A-P) } \\
\text { length (\%) }\end{array}$ & $((P 4+P 5) \div 2) \div((P 9+P 10) \div 2)$ \\
\hline
\end{tabular}

Appointment System (PAS). The lying cadaver stature in centimetre $(\mathrm{cm})$ for post-mortem subjects was measured during autopsy examinations and retrieved from post-mortem reports whilst the standing height for living patients was retrieved from registration folders and forms or confirmed by contacting the respective patients. Cases were excluded if the history highlighted conditions or events that could have affected bone morphology of the sacrum, for example vertebral fracture, burning, anomalies such as tumours, or diseases. Distorted CT images were also excluded from the sample.

\section{Data acquisition and reconstruction}

The sacrum bones were first viewed and segmented through multi-planar reconstruction (MPR) and 3D image reconstruction using the software Mimic $\mathrm{Re}$ search 17.0 available at the School of Dental Sciences, Universiti Sains Malaysia. Linear measurements were taken in centimetre $(\mathrm{cm})$ at 2 decimal points by using the software 3D Builder as adopted by Garvin and Severa (Garvin and Severa, 2019) based on Fig. 1 and Tables 2 and 3 (Kanika et al., 2011, Shreekrishna et al., 2013). Measurements of all subjects were taken twice to satisfy the intra-observer error analysis. Subsequently, a total of $10 \%$ of the subjects were randomly selected for inter-observer error analysis and measured twice by another observer from KLH. Relative technical error of measurement (TEM) which is acceptable if less than 5\% for each parameter was calculated using equations described previously (Perini et al., 2005).

\section{Statistical analysis}

The Kolmogorov-Smirnov test $(N>100)$ was first conducted to determine normality at $p>0.05$ for all parameters after removing all outliers. Correlation analyses were performed using the Statistical Package for the Social Sciences (SPSS) version 24 to determine the relationship between sacral morphometrics and the stature of subjects according to sex and ancestry. Regression analyses were then conducted using well-correlated parameters, and regression coefficients were identified for each generated formula. Further validation analysis of the regression formulae on stature was conducted by using 56 holdout subjects (28 males and 28 females), i.e. 15\% split from the total subjects (Mahakkanukrauh et al., 2011). The remaining $85 \%$ of the total subjects were used to generate new regression formulae from this study to be tested using the holdout subjects. Tests were performed by estimating the stature of each individual and comparing it to the actual stature of the holdout subjects. Subsequently, the absolute value of the error for each estimate was taken to compute the mean for absolute error.

\section{Results and discussion Normality test}

Descriptive statistics for stature and normality were assumed based on the Kolmogorov-Smirnov (K-S) test at $p>0.05$ as shown in Table 4 . The stature of the selected subjects was normally distributed based on the histogram. This showed that the stature distribution during subject selection was unbiased and acceptable for statistical analysis. A total of ten parameters were measured in this study to generate six indices of sacral morphometric analysis for biological profiling. Overall descriptive statistics of the selected subjects are listed in Table 5. The KolmogorovSmirnov (K-S) test showed that normality was

Table 4 Descriptive statistics for age and stature of subjects selected

\begin{tabular}{llllll}
\hline No. & $N$ & Minimum-maximum & Mean \pm standard error & Standard deviation & K-S test sig. value \\
\hline Stature & 361 & $125.00-186.00$ & $161.26 \pm 0.48$ & 9.20 & $0.200^{*}$ \\
\hline
\end{tabular}

Unit in centimetre $(\mathrm{cm})$

${ }^{*} p>0.05$ whereby normality is assumed 
Table 5 Descriptive statistics for parameters and indices of sacral morphometric

\begin{tabular}{llllll}
\hline No. & N & Minimum-maximum & Mean \pm standard error & Standard deviation & K-S test sig. value \\
\hline P1 & 363 & $9.64-12.59$ & $11.01 \pm 0.03$ & 0.58 & $0.061^{*}$ \\
P2 & 373 & $2.83-7.14$ & $4.76 \pm 0.03$ & 0.67 & $0.200^{*}$ \\
P3 & 367 & $1.99-3.93$ & $3.06 \pm 0.02$ & 0.32 & $0.170^{*}$ \\
P4 & 373 & $1.60-4.51$ & $3.12 \pm 0.02$ & 0.40 & $0.200^{*}$ \\
P5 & 372 & $1.58-4.37$ & $3.09 \pm 0.02$ & 0.40 & $0.200^{*}$ \\
P6 & 373 & $6.59-12.59$ & $10.14 \pm 0.05$ & 0.99 & $0.200^{*}$ \\
P7 & 373 & $3.98-7.46$ & $5.43 \pm 0.03$ & 0.59 & $0.163^{*}$ \\
P8 & 373 & $3.53-7.38$ & $5.50 \pm 0.03$ & 0.62 & $0.200^{*}$ \\
P9 & 364 & $3.69-6.67$ & $5.21 \pm 0.03$ & 0.55 & 0.026 \\
P10 & 364 & $3.91-6.41$ & $5.18 \pm 0.03$ & 0.53 & 0.004 \\
I1 (\%) & 359 & $84.66-137.50$ & $108.64 \pm 0.51$ & 9.69 & $0.077^{*}$ \\
I2 (\%) & 363 & $25.84-59.95$ & $43.45 \pm 0.31$ & 5.85 & $0.172^{*}$ \\
I3 (\%) & 365 & $43.64-86.85$ & $64.55 \pm 0.34$ & 6.50 & $0.200^{*}$ \\
I4 (\%) & 367 & $33.89-112.50$ & $66.44 \pm 0.72$ & 13.88 & $0.069^{*}$ \\
I5 (\%) & 363 & $35.34-65.96$ & $49.95 \pm 0.28$ & 5.37 & $0.200^{*}$ \\
16 (\%) & 358 & $42.27-85.65$ & $59.87 \pm 0.44$ & & $0.184^{*}$ \\
\hline Un & & & & \\
\hline
\end{tabular}

Unit in centimetre $(\mathrm{cm})$

${ }^{*} p>0.05$ whereby normality is assumed

assumed at $p>0.05$ for all sacral parameters and indices except the alae anteroposterior (A-P) lengths (P9 and P10). However, the boxplots of both parameters were normally distributed according to the central spread of the parameter measurements; only a slightly negative skewness was recorded.

\section{Bilateral symmetry analysis}

From the results shown in Table 6, a significant difference between the right side and the left side of the sacrum exists according to the paired test $(p<$ 0.05). As such, both sides of the alae and auricular surface were measured to consider the bilateral asymmetry of the sacrum. The average of both sides was then used for index calculations. This is consistent with Kurki (2017) whereby the pelvic girdle was found to be bilaterally asymmetric due to multiple selective factors including obstetrics, bipedal locomotion and environmental factors such as biomechanical loading effects.

\section{Intra-observer and inter-observer analyses}

Kevin Norton's and Tim Old's methodology was applied in several previous studies by computing the technical error of measurements (TEM) as well as the coefficient of reliability (Goto and Nicholas, 2007, Jamaiyah et al., 2010, Perini et al., 2005). In this study, duplicate readings for each parameter were taken by both observer 1 and observer 2 to compensate for the intra-observer error on each of the parameters measured based on 35 randomly selected subjects, i.e. $10 \%$ of the total subjects. There was no significant difference between reading 1 and reading 2 for both observer 1 and observer 2 based on the paired sample $t$ test at $p>0.05$. Similar results were obtained for inter-observer analysis whereby the relative TEM for each parameter within and between the observers were all lower than $5 \%$ and reliability was higher than 0.8 .

\section{Correlation and regression analyses}

A total of 186 males and 175 females had been selected for stature estimation using correlation and

Table 6 Paired sample statistics for symmetry analysis of sacral morphometrics

\begin{tabular}{llllll}
\hline No. & $\mathrm{N}$ & Paired Samples Correlation & Correlation Sig. Value & t value & Paired Samples Sig. Value \\
\hline Pair 1: P4 \& P5 & 372 & 0.757 & $<0.001$ & 2.045 & $0.042^{*}$ \\
Pair 2: P7 \& P8 & 373 & 0.853 & $<0.001$ & -3.916 & $<0.001^{*}$ \\
Pair 3: P9 \& P10 & 363 & 0.835 & $<0.001$ & 2.196 & $0.029^{*}$ \\
\hline
\end{tabular}

Note: * represents $p<0.05$ whereby significant difference is assumed 
Table 7 Correlation and regression statistics for individual parameters and indices of sacral morphometric against stature in validation analysis

\begin{tabular}{|c|c|c|c|c|c|c|c|}
\hline No. & $N$ & Regression formula & SEE & $R$ value & Mean Abs deviation & MSE & AWR (\%) \\
\hline P1 & 297 & $131.903+2.711(\mathrm{P} 1)$ & 8.714 & $0.178^{*}$ & 6.759 & 64.648 & 75.00 \\
\hline P2 & 305 & $152.298+1.900(\mathrm{P} 2)$ & 9.305 & $0.143^{*}$ & 6.550 & 62.834 & 76.79 \\
\hline P3 & 299 & $126.885+11.304(\mathrm{P} 3)$ & 8.488 & $0.393^{*}$ & 4.988 & 40.279 & 87.50 \\
\hline P4 & 305 & $155.764+1.794(\mathrm{P} 4)$ & 9.373 & -0.078 & 6.815 & 67.296 & 71.43 \\
\hline P5 & 304 & $153.663+2.500(\mathrm{P} 5)$ & 9.342 & -0.109 & 6.920 & 68.399 & 71.43 \\
\hline P6 & 305 & $125.401+3.531(\mathrm{P} 6)$ & 8.739 & $0.369^{*}$ & 7.185 & 72.318 & 71.43 \\
\hline P7 & 305 & $115.031+8.504(\mathrm{P} 7)$ & 7.973 & $0.530^{*}$ & 5.719 & 48.094 & 78.57 \\
\hline P8 & 305 & $114.619+8.480(\mathrm{P} 8)$ & 7.813 & $0.556^{*}$ & 5.210 & 39.879 & 78.57 \\
\hline P9 & 296 & $141.601+3.813(P 9)$ & 8.890 & $0.231^{*}$ & 6.596 & 61.576 & 76.79 \\
\hline P10 & 296 & $142.825+3.612(\mathrm{P} 10)$ & 8.908 & $0.213^{*}$ & 6.515 & 61.074 & 78.57 \\
\hline 11 & 293 & $185.969-0.224(11)$ & 8.656 & $-0.235^{*}$ & 7.064 & 71.343 & 67.86 \\
\hline 12 & 297 & $161.977-0.004(12)$ & 8.855 & -0.003 & 6.777 & 67.042 & 67.86 \\
\hline 13 & 297 & $138.759+0.353(13)$ & 8.955 & $0.252^{*}$ & 6.118 & 57.711 & 80.36 \\
\hline 14 & 299 & $162.858-0.022(14)$ & 9.463 & -0.033 & 6.669 & 65.328 & 75.00 \\
\hline 15 & 297 & $127.861+0.679(15)$ & 8.081 & $0.409^{*}$ & 5.823 & 50.828 & 82.14 \\
\hline 16 & 290 & $169.042-0.126(16)$ & 9.095 & $-0.118^{*}$ & 6.536 & 62.600 & 75.00 \\
\hline
\end{tabular}

Unit in centimetre $(\mathrm{cm})$; highly significant results are in bold

SEE standard error of estimation for the generated regression formula, $R$ value Pearson correlation coefficient, MSE mean squared error, AWR accuracy percentage of estimated stature within SEE range compared to actual stature

${ }^{*} p<0.05$ whereby significant correlation and regression are assumed

regression analysis based on the parameters and indices as listed in Table 7. Sacral basal width (P1), S1 body diameters (P2 and P3), sacral height (P6), alae A$\mathrm{P}$ lengths (P9 and P10), S1 body index (I3) and auricular index (I5) recorded a relatively significant positive correlation with stature at $R<0.500$. However, the sacral index (I1) and alae diagonal index (I6) recorded a relatively significant negative correlation with stature at $R<-0.200$. All these parameters were considered in combination for the regression formula for combined sex with higher $R$ values as listed in Table 8 .

In addition, auricular lengths (P7 and P8) were recorded as the most comparatively useful stature estimators at the positive correlation coefficient, $R>$
0.500 at $p<0.001$. However, Zhan et al. (2018) reported relatively lower $R$ values for auricular length and A-P diameter of S1 body (P3) but higher for sacral basal width (P1) for the Chinese population in China compared to the Malaysian population. Having said that, the $R$ value determined in this study for P2 and P6 recorded relatively lower values compared to other studies as listed in Table 9 (Pelin et al. 2005; Giroux and Wescott, 2008; Pininski and Brits, 2014; Torimitsu et al. 2017; Wagner et al. 2017; Zhan et al. 2018). This shows that the regression formulae are totally dependent on the study population according to each individual parameter and index being applied.

Table $\mathbf{8}$ Correlation and regression statistics for combination of parameters and indexes of sacral morphometric against stature in validation analysis

\begin{tabular}{|c|c|c|c|c|c|c|}
\hline Regression Formula & SEE & $\mathrm{N}$ & R Value & $\begin{array}{l}\text { Mean Abs } \\
\text { Deviation }\end{array}$ & MSE & AWR (\%) \\
\hline $122.360-0.059 * 11+0.3773 * 13+0.575 * 15-0.116^{*} 16$ & 7.901 & 279 & $0.486^{*}$ & 5.397 & 46.737 & 80.36 \\
\hline $90.117+1.008^{*} \mathbf{P} 1-5.061{ }^{*} \mathbf{P} 2+9.275^{*} \mathbf{P} \mathbf{3}+0.718^{*} \mathbf{P} 6+2.107^{*} \mathbf{P} 7+4.726^{*} \mathbf{P} 8+3.153^{*} \mathbf{P} \mathbf{9}-0.999^{*} \mathbf{P} 10$ & 7.138 & 286 & $0.615^{*}$ & 4.836 & 36.191 & 76.79 \\
\hline $\begin{array}{l}\text { 155.927-7.098*P1- 6.073*P2+9.397*P3+ 3.262*P6+9.258*P7+ 12.337*P8+1.586*P9- } \\
1.782^{*} \mathbf{P} 10+0.213^{*} \mathbf{1}+0.016^{*} \mathbf{I}-1.620^{*} \mathbf{1 5}-0.168^{*} \mathbf{1 6}\end{array}$ & 7.112 & 277 & $0.633^{*}$ & 4.942 & 37.317 & 76.79 \\
\hline
\end{tabular}

Note: unit in centimetre (cm); SEE represents the standard error of estimation for the generated regression formula; $\mathrm{R}$ value represents the Pearson correlation coefficient; MSE represents mean squared error; AWR represents the accuracy percentage of estimated stature within SEE range compared to actual stature; * represents $p<0.05$ whereby significant correlation and regression are assumed 


\section{Validation analysis}

Further validation analysis on the regression formulae was conducted by using holdout samples of 28 males and 28 females. The remaining $85 \%$ of subjects were used to generate new regression formulae for each parameter and index. The stature estimated using the generated formulae was compared to the actual stature of the holdout subjects. The mean absolute deviation (MAD) ranged from 4.988 to 7.185 $\mathrm{cm}$ which are lower than the standard error of estimation (SEE) of the respective regression formulae. The stature estimation based on the anteroposterior diameter of S1 body (P3) recorded the lowest MAD and mean squared error (MSE) with the highest accuracy at $87.50 \%$ within the SEE range, followed by auricular length (P7 and P8) though with a slightly lower accuracy rate within SEE range as shown in Table 7.

As shown in Figs. 2 and 3, the regression formulae for both transverse diameter of S1 body (P2) and sacral height (P6) generated from previous studies on Africans (2014) and Japanese (2017) were applied and tested using the similar holdout subjects, and the results were compared to the formula generated in this study. The formula for Africans tends to overestimate both parameters (P2 and P6) whilst the formula for Malaysians generated in this study produced lower MAD and MSE rates at higher accuracy within the SEE range as summarised in Table 10. The estimated stature based on the formula for Japanese was totally out of the range compared to the holdout subjects' actual stature. This validates that the population-specific formula generated in this study should only be applied to the Malaysian population among the ancestry subgroups that were included in this study.

In the application of scientific human skeletal variation in medico-legal matters, virtual anthropology using CT scan is the current technique performed to examine skeleton remains. This is an important method replacing the conventional method, i.e. direct physical examination of skeletal remains for identification purposes as it saves both cost and time. A related study showed that there was no significant difference in the measurements calculated using the conventional and virtual methods; nonetheless, the virtual method was shown to be more accurate and reliable compared to the conventional method (Ismail et al., 2019).

Table 9 Comparison of regression analysis reported by the previous studies and the present study for stature estimation

\begin{tabular}{|c|c|c|c|c|c|c|c|c|c|c|}
\hline Authors & Modalities & Population & Sex & $\begin{array}{l}\text { Sample } \\
\text { size }\end{array}$ & Formula P2 & SEE & $R$ & Formula P6 & SEE & $R$ \\
\hline Pelin et al. (2005) & MRI & Caucasian & Male & 42 & & & & $142.79+2.58 \times P 6$ & \pm 6.59 & 0.432 \\
\hline \multirow{4}{*}{$\begin{array}{l}\text { Giroux and } \\
\text { Wescott (2008) }\end{array}$} & \multirow[t]{4}{*}{ Dry bone } & \multirow[t]{2}{*}{ Black American } & Male & 57 & & & & $143.773+3.117 \times P 6$ & \pm 6.96 & 0.460 \\
\hline & & & Female & 38 & & & & $133.675+2.898 \times P 6$ & \pm 7.21 & 0.440 \\
\hline & & \multirow[t]{2}{*}{ White American } & Male & 92 & & & & $149.812+2.461 \times P 6$ & \pm 7.17 & 0.390 \\
\hline & & & Female & 60 & & & & $154.003+0.883 \times P 6$ & \pm 7.73 & 0.130 \\
\hline \multirow[t]{6}{*}{ Pininski and Brits (2014) } & \multirow[t]{6}{*}{ Dry bone } & \multirow[t]{3}{*}{ Black African } & Male & 50 & $155.320+2.976 \times P 2$ & \pm 6.95 & 0.260 & $139.892+3.193 \times P 6$ & \pm 6.69 & 0.370 \\
\hline & & & Female & 58 & $157.591+0.727 \times P 2$ & \pm 6.93 & 0.050 & $126.979+3.694 \times P 6$ & \pm 5.90 & 0.530 \\
\hline & & & Overall & 108 & $137.928+5.468 \times P 2$ & \pm 8.03 & 0.390 & $118.867+4.930 \times P 6$ & \pm 7.30 & 0.550 \\
\hline & & \multirow[t]{3}{*}{ White African } & Male & 51 & $152.770+3.496 \times P 2$ & \pm 8.52 & 0.250 & $148.650+2.298 \times P 6$ & \pm 8.53 & 0.250 \\
\hline & & & Female & 51 & $149.037+2.684 \times P 2$ & \pm 6.76 & 0.240 & $139.373+2.353 \times P 6$ & \pm 6.59 & 0.330 \\
\hline & & & Overall & 102 & $140.112+5.093 \times P 2$ & \pm 8.55 & 0.370 & $136.261+3.084 \times P 6$ & \pm 8.71 & 0.320 \\
\hline \multirow[t]{3}{*}{ Torimitsu et al. (2017) } & \multirow[t]{3}{*}{ CT } & \multirow[t]{3}{*}{ Japanese } & Male & 110 & & & & $132.69+0.32 \times P 6$ & \pm 5.98 & 0.216 \\
\hline & & & Female & 106 & & & & $115.33+0.38 \times \mathrm{P} 6$ & \pm 7.84 & 0.220 \\
\hline & & & Overall & 216 & & & & $104.45+0.53 \times P 6$ & \pm 8.29 & 0.345 \\
\hline Wagner et al. (2017) & $C T$ & European & Overall & 75 & & & & & & 0.371 \\
\hline \multirow[t]{2}{*}{ Zhan et al. (2018) } & \multirow[t]{2}{*}{ CT } & \multirow[t]{2}{*}{ Chinese } & Male & 190 & & & & $136.477+2.662 \times P 6$ & \pm 5.83 & 0.416 \\
\hline & & & Female & 160 & & & & $133.867+1.948 \times P 6$ & \pm 5.55 & 0.294 \\
\hline \multirow[t]{3}{*}{ Present study (2019) } & \multirow[t]{3}{*}{ CT } & \multirow[t]{3}{*}{ Malaysian } & Male & 186 & $162.440+0.850 \times P 2$ & \pm 7.53 & 0.075 & $146.889+1.909 \times P 6$ & \pm 7.32 & 0.243 \\
\hline & & & Female & 175 & $151.658+0.851 \times P 2$ & \pm 7.25 & 0.077 & $129.631+2.605 \times P 6$ & \pm 6.78 & 0.356 \\
\hline & & & Overall & 361 & $151.123+2.131 \times P 2$ & \pm 9.10 & 0.156 & $129.907+3.091 \times P 6$ & \pm 8.69 & 0.332 \\
\hline
\end{tabular}






\section{Conclusion}

This study is important for instances when incomplete unknown human remains are recovered from scenes, especially when long limbs are unavailable for stature estimation. The auricular lengths (P7 and P8) were the most comparatively useful stature estimators at $R>0.5$. Previously constructed regression formulae were found to be totally dependent on the respective study populations for each individual parameter and index applied. The combination of sacral parameters and indices had contributed to a higher correlation regression coefficient. The population-specific formula of combined sex generated from this study should only be applied and be a guideline within the Malaysian population, specifically for the Malay, Chinese and Indian community although the SEE is relatively high compared to those recorded for long bones and pelvic bones. To conclude, this populationspecific study based on sacral bones among Malaysians helps to enhance the existing database used by forensic anthropologists and forensic radiologists to perform stature estimation especially when examining skeletal parts of incomplete and unknown human remains. In the future, researchers of similar area of interest are recommended to further explore other bony parts of the sacral bones up to the extension of the entire pelvis or pelvic girdle, especially for stature estimation studies. 


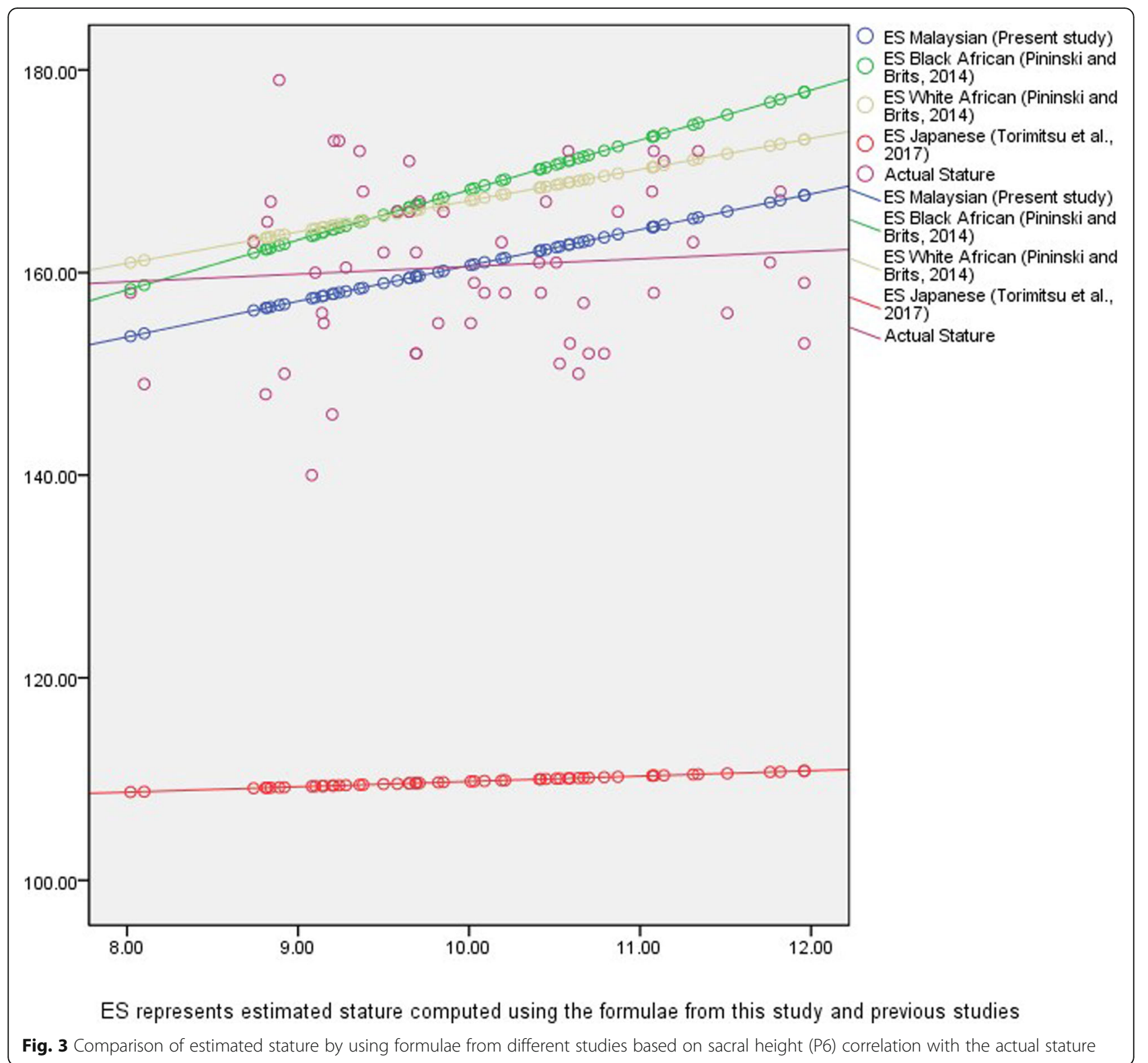

Table 10 Comparison of estimated stature by using formulae from different studies in validation analysis

\begin{tabular}{|c|c|c|c|c|c|c|}
\hline \multicolumn{4}{|c|}{ Transverse diameter S1 body (P2) } & \multicolumn{3}{|l|}{ Sacral height (P6) } \\
\hline Regression formula & Mean Abs deviation & Mean squared error & AWR (\%) & Mean Abs deviation & Mean squared error & AWR (\%) \\
\hline Black African & 6.607 & 68.988 & 69.64 & 9.741 & 140.346 & 41.07 \\
\hline White African & 6.734 & 71.613 & 71.43 & 8.650 & 113.181 & 55.36 \\
\hline Japanese & - & - & - & 50.868 & 2652.699 & 0.00 \\
\hline Present study & 6.550 & 62.834 & 76.79 & 7.185 & 72.318 & 71.43 \\
\hline
\end{tabular}

Unit in centimetre $(\mathrm{cm})$

AWR the accuracy percentage of estimated stature within SEE range compared to actual stature 


\section{Abbreviations}

3D: Three-dimension; A-P: Anteroposterior; CT: Computed tomography; DICOM: Digital Imaging and Communication in Medicine; FMIS: Forensic Medicine Information System; KLH: Kuala Lumpur Hospital; K-S: KolmogorovSmirnov; MAD: Mean absolute deviation; MPR: Multi-planar reconstruction; MRI: Magnetic resonance imaging; MSCT: Multi-slice computed tomography; MSE: Mean squared error; NIFM: National Institute of Forensic Medicine; PACS: Picture Archiving and Communication Systems; PAS: Patient Appointment System; SEE: Standard error of estimation; SH: Sacrum height; SPSS: Statistical Package for the Social Sciences; TEM: Technical error of measurement

\section{Acknowledgements}

The authors thank the Director General of Health Malaysia for his permission to publish this article. Also, we would like to express our gratitude to Universiti Sains Malaysia (USM) and Kuala Lumpur Hospital $(H K L)$ for giving opportunity the use of resources throughout the research. In particular, the Human Research Ethics Committee (HREC) of the USM and Medical Research Ethics Committee (MREC) of the Ministry of Health $(\mathrm{MOH})$ for the ethics approval and permission to conduct the research. Not to forget to recognise the assistance of Dr. Johari Yap in providing guidance on the software Mimics Research 17.0 available at the School of Dental Sciences, USM. Thank you for the tremendous guidance given along with the research support on data and statistical analysis especially contributed by biostatistician Dr. Mohamad Arif Awang Nawi. Last but not least, a great appreciation to forensic scientific officers, radiographers and staff nurse Ms. Choo Mei Jie from the HKL for commitment, patience and involvement in overcoming numerous obstacles whilst conducting the research and observer analysis.

\section{Consent to participate}

Not applicable (retrospective data acquired under ethics approval by the Medical Research Ethics Committee of Ministry of Health, Malaysia).

\section{Authors' contributions}

LPS contributed to the conceptualization, methodology, software, validation, formal analysis, investigation, resources, data curation, writing of the original draft, writing of the review and editing, visualization and project administration. MHMN contributed to the methodology, writing of the review and editing, validation, supervision and resources. NA contributed to the methodology, writing of the review and editing, supervision and resources. $\mathrm{HH}$ contributed to the conceptualization, formal analysis, supervision, writing of the review and editing, project administration, methodology, visualization and software. All authors read and approved the final manuscript.

\section{Availability of data and materials}

Data is not available for public access and password protected and kept by the principal investigators in order to meet the ethical requiremens of the research.

\section{Ethics approval and consent to participate}

Ethical approval reference number KKM.NIHSEC.P18-2350(7) and registered under National Medical Research Registry (NMRR-18-3132-44576), Ministry of Health, Malaysia.

\section{Consent for publication}

Not applicable.

\section{Competing interests}

The authors declare that they have no known competing financial interests or personal relationships that could have appeared to influence the work reported in this paper.

\section{Author details}

'Department of Forensic Science, School of Health Science, Universiti Sains Malaysia, Kubang Kerian, Malaysia. ${ }^{2}$ Radiology Department, Kuala Lumpur Hospital, Kuala Lumpur, Malaysia. ${ }^{3}$ Institute of Forensic Medicine Malaysia, Kuala Lumpur Hospital, Kuala Lumpur, Malaysia.
Received: 2 December 2019 Accepted: 11 June 2020

Published online: 29 June 2020

\section{References}

Barbara F, Philipp M (2015) Covariation between human pelvis shape, stature, and head size alleviates the obstetric dilemma. Proceedings of the National Academy of Sciences of the United States of America, 112, 5655-5660.

Garvin HM, Severa K (2019) An alternative method to using a mandibulometer. J Forensic Sci: $1-6$

Giroux CL, Wescott DJ (2008) Stature estimation based on dimensions of the bony pelvis and proximal femur. J Forensic Sci 53:65-68

Goto R, Nicholas MTCG (2007) Precision of measurement as a component of human variation. J Physiol Anthropol 26:253-256

Hakki MK, Osman C, Ahmet H, Banu A (2011) Total body height estimation using sacrum height in Anatolian Caucasians: multidetector computed tomography-based virtual anthropometry. Skelet Radiol 40:623-630

Ismail NA, Abdullah N, Noor MHM, Lai PS, Shafie MS, Nor FM (2019) Accuracy and reliability of virtual femur measurement from $\mathrm{CT}$ scan. J Forensic Legal Med 63:11-17

Jamaiyah H, Geeta A, Safiza M, Khor G, Wong N, Kee C, Rahmah R, Ahmad A, Suzana S, Chen W (2010) Reliability, technical error of measurements and validity of length and weight measurements for children under two years old in Malaysia. Med J Malays 65:131-137

Kanika S, Rajan KS, Gurdeep K, Gaurav S (2011) Role of sacrum in sexual dimorphism: a morphometric study. J Indian Acad Forensic Med 33: 206-210

Kurki HK (2017) Bilateral asymmetry in the human pelvis. Anat Rec 300: 653-665

Linda LK (2006) Fundamentals of forensic anthropology. Wiley, New Jersey, USA

Mahakkanukrauh P, Khanpetch P, Prasitwattanseree S, Vichairat K, Case DT (2011) Stature estimation from long bone lengths in a Thai population. Forensic Sci Int 210:279. e1-279. e7

Megan KM, Ann HR (2013) Stature estimation. In: Elizabeth AD, Megan KM (eds) Research methods in human skeleton biology, 1st edn. Academic Press, Massachusetts, USA

Özaslan A, Işcan MY, Özaslan IN, Tuğcu H, Koç S (2003) Estimation of stature from body parts. Forensic Sci Int 132:40-45

Pelin C, Duyar I, Kayahan EM, Zagyapan R, Agildere AM, Esra A (2005) Body height estimation based on dimensions of sacral and coccygeal vertebrae. J Forensic Sci 50:294-297

Perini TA, Oliveira GL, Ornellas JS, Oliveira FP (2005) Technical error of measurement in anthropometry. Rev Bras Med Esporte 11:81-85

Pininski M, Brits D (2014) Estimating stature in south African populations using various measures of the sacrum. Forensic Sci Int 234:182.e1-182.e7

Shreekrishna H, Yatiraj S, Vijayakumari N (2013) Credibility of various indices of sacrum in identification of sex of sacrum. Int J Med Toxicol Forensic Med 3: $58-63$

Standring S (2015) Gray's anatomy international edition: the anatomical basis of clinical practice. Elsevier Health Sciences, London, UK

Torimitsu S, Makino Y, Saitoh H, Ishii N, Hayakawa M, Yajima D, Inokuchi G, Motomura A, Chiba F, Iwase H (2014) Stature estimation in Japanese cadavers using the sacral and coccygeal length measured with multidetector computed tomography. Legal Med 16:14-19

Torimitsu S, Makino Y, Saitoh H, Sakuma A, Ishii N, Hayakawa M, Yajima D, Inokuchi G, Motomura A, Chiba F (2015) Stature estimation in Japanese cadavers based on pelvic measurements in three-dimensional multidetector computed tomographic images. Int J Legal Med 129: 633-639

Torimitsu S, Makino Y, Saitoh H, Sakuma A, Ishii N, Yajima D, Inokuchi G, Motomura A, Chiba F, Yamaguchi R, Hashimoto M, Hoshioka Y, Iwase H (2017) Sex determination based on sacral and coccygeal measurements using multidetector computed tomography in a contemporary Japanese population. J Forensic Radiol Imaging 9:8-12

Wagner D, Kamer L, Sawaquchi T, Richards RG, Noser H, Hofmann A, Rommens PM (2017) Morphometry of the sacrum and its implication on trans-sacral corridors using a computed tomography data-based three-dimensional statistical model. Spine J 17:1141-1147 
Wiley P (2016) Stature estimation. In: Soren B, Douglas HU (eds) Handbook of forensic anthropology and archaeology, 2nd edn. Taylor \& Francis, New York, USA

Zhan MJ, Fan F, Qiu LR, Peng Z, Zhang K, Deng ZH (2018) Estimation of stature and sex from sacrum and coccyx measurements by multidetector computed tomography in Chinese. Legal Med 34:21-26

\section{Publisher's Note}

Springer Nature remains neutral with regard to jurisdictional claims in published maps and institutional affiliations.

Submit your manuscript to a SpringerOpen ${ }^{\circ}$ journal and benefit from:

- Convenient online submission

- Rigorous peer review

- Open access: articles freely available online

- High visibility within the field

- Retaining the copyright to your article

Submit your next manuscript at $\boldsymbol{\nabla}$ springeropen.com 